\title{
Lumican expression in gastric cancer and its association with biological behavior and prognosis
}

\author{
LI CHEN $^{1}$, YUXIN ZHANG ${ }^{1}$, YANJIAO ZUO ${ }^{1}$, FEI MA $^{2}$ and HONGJIANG SONG ${ }^{1}$ \\ Departments of ${ }^{1}$ Gastrointestinal Surgery and ${ }^{2}$ Breast Surgery, Harbin Medical University Cancer Hospital, \\ Harbin Medical University, Harbin, Heilongjiang 150081, P.R. China
}

Received March 24, 2016; Accepted June 16, 2017

DOI: $10.3892 / \mathrm{ol} .2017 .6842$

\begin{abstract}
The aim of the present study was to investigate the expression of lumican in human gastric cancer and adjacent normal gastric tissues, and study its association with clinicopathological characteristics and survival rate. By using immunohistochemistry, the lumican expression patterns in 146 cases of gastric cancer with various clinicopathological characteristics 55 adjacent normal gastric tissue specimens was studied. And the significance of lumican expression regarding the biological behavior and survival of patients was evaluated. In adjacent normal gastric tissues, lumican was expressed weakly in $10.9 \%(6 / 55)$ of samples. By contrast, the lumican expression rate was $66.4 \%(97 / 146)$ in gastric cancer tissues. Lumican protein expression was closely associated with organ metastasis, lymphatic metastasis and histological type $(\mathrm{P}<0.05)$, but not with the tumor location, size, invasion depth or Borrmann type $(\mathrm{P}>0.05)$. The median survival time in patients with negative, weakly positive and strongly positive lumican expression was 46.3, 39.6 and 24.3 months, respectively $\left(\chi^{2}=8.492 ; P=0.014\right)$. There was a significant association between lumican expression and invasive potential in gastric cancer; therefore, lumican may represent an independent prognostic factor.
\end{abstract}

\section{Introduction}

Gastric cancer is one of the most common malignant tumors, and the major cause of cancer-associated mortality worldwide $(1,2)$. The World Health Organization (WHO) and International Arctic Research Center indicates that the global incidence of gastric cancer is 952,000 , with 405,000 patients in China, accounting for $42.6 \%$ of the global incidence (3). In China, the majority of patients are diagnosed in advanced

Correspondence to: Professor Hongjiang Song, Department of Gastrointestinal Surgery, Harbin Medical University Cancer Hospital, Harbin Medical University, 150 Haping Road, Harbin, Heilongjiang 150081, P.R. China

E-mail: hongjiangsong2016@163.com

Key words: lumican, gastric cancer, small leucine-rich proteoglycans gastric cancer, $10 \%$ patients are the early stage gastric cancer, and the 5-year survival rate is $10-30 \%$ (4). The pathogenesis of gastric cancer is a complex multi-step process resulting from the accumulation of multiple genes. As important components of the extracellular matrix, proteoglycans are involved in the occurrence and invasiveness of cancer. Small leucine-rich proteoglycans (SLRPs) not only regulate the extracellular osmotic pressure, but also affects tissue biomechanics $(5,6)$ and serves a notable role in tumor growth, proliferation, adhesion, migration and the regulation of growth factor activity $(7,8)$. As an important member of SLRP, lumican is thought to modify the fibrous tissue and induce a tumor-specific ECM (9). Lumican has its own unique structure and certain special functions that can affect tumor occurrence and development, processes that remain to be understood $(10,11)$.

To investigate the function of lumican during the occurrence and development of gastric cancer, lumican expression was assessed by immunohistochemistry in gastric cancer tissues, and adjacent normal gastric tissues. The aim of the present study was to investigate the lumican expression in gastric cancer and its association with biological behavior and prognosis.

\section{Materials and methods}

Materials. The present study was approved by the Ethics committee of Harbin Medical University Cancer Hospital, Harbin Medical University (Harbin, China) and informed consent was obtained from all patients. The retrospective analysis enrolled 146 patients with gastric cancer which were confirmed in accordance with pathological evidence, and 55 adjacent normal gastric tissue specimens obtained. All patients were radical correction or enlarged radical correction in the Department of Gastrointestinal Surgery, Harbin Medical University Cancer Hospital, Harbin Medical University (Harbin, China) from June 2010 to December 2010. Of the 146 patients, 110 patients were male and 36 were female, with a mean age of 57.1 years (range $30-75$ years). Selection criteria included: i) A pathological diagnosis of adenocarcinoma; ii) no pre-operative radiotherapy or chemotherapy; iii) complete clinical data and follow-up; iv) no other serious organ diseases; v) patients had succumbed to the disease as a result of tumor recurrence or metastasis; vi) all adjacent normal tissues were sourced $>5 \mathrm{~cm}$ away from the edge of the cancerous tissue. 

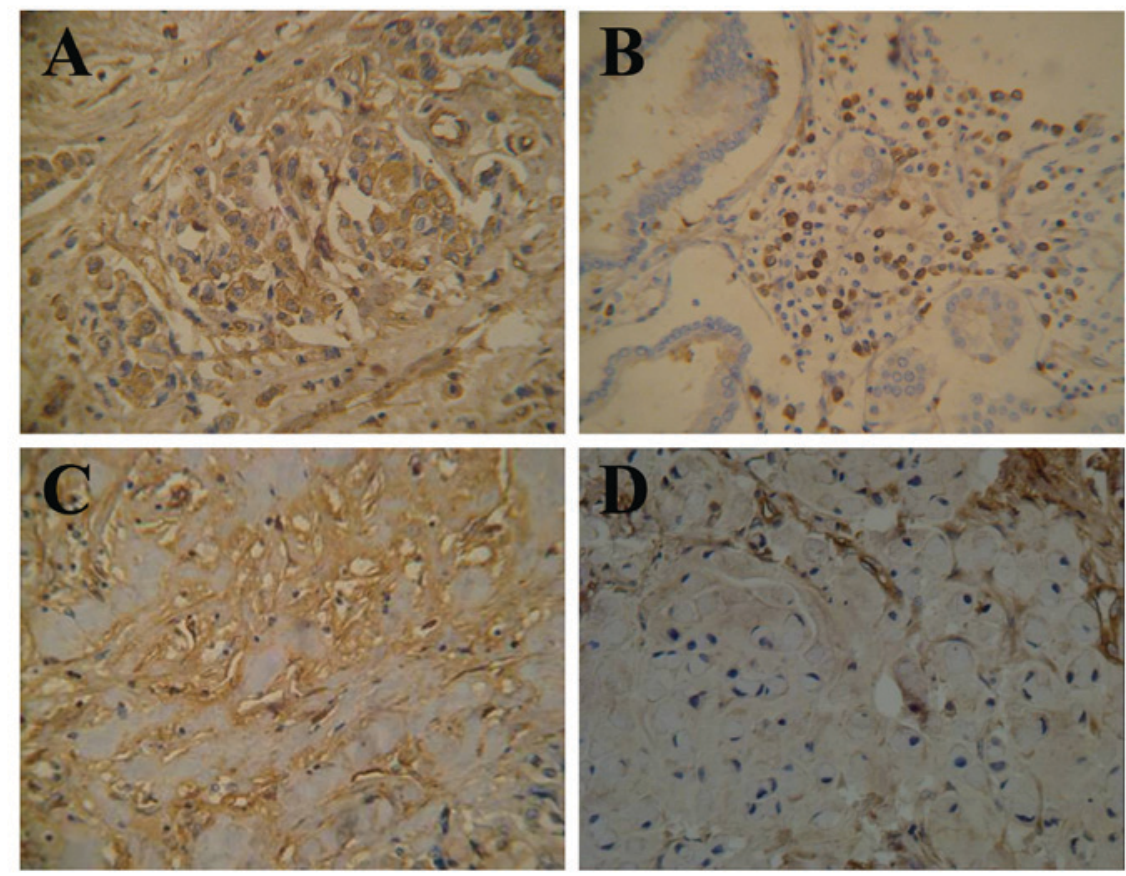

Figure 1. Expression of lumican in adjacent normal gastric tissues and gastric cancer tissues (magnification, $\mathrm{x} 400$ ). (A) Expression of lumican in adjacent normal gastric tissue. (B) Expression of lumican in gastric adenocarcinoma tissue. (C) Expression of lumican in gastric mucinous adenocarcinoma tissue. (D) Expression of lumican in gastric signet-ring cell carcinoma tissue.

Immunohistochemistry. Goat polyclonal lumican antibody (cat. no. AF2846; R\&D Systems, Inc., Minneapolis, MN, USA) diluted to 1:50 were used as the primary antibody. The SP-9003 Immunohistochemistry kit was obtained from Origene Technologies, Inc., (Beijing, China). A polyclonal antibody against the human lumican protein used for immunohistochemistry was obtained as previously reported (12). Immunohistochemical analysis was performed using the Histofine Simple Stain $\mathrm{PO}^{\circledR}$ Max kit (Nichirei Corporation, Tokyo, Japan). The present study used dimethylbenzene to wash the slides three times for $5 \mathrm{~min}$ to deparaffinize, dehydrated slides with sequential concentrations of ethanol $(100,90,80$ and $70 \%$, for 3 min each). Endogenous peroxidase activity was blocked by incubation in $0.3 \%$ hydrogen peroxide in methanol for $30 \mathrm{~min}$ at $37^{\circ} \mathrm{C}$. The tissue sections (3-4 $\mu \mathrm{m}$-thick) were incubated with the anti-human lumican antibody (cat. no. AF2846; R\&D Systems, Inc.) diluted to 1:100 in PBS containing 1\% bovine serum albumin (Institute of Hematology, Chinese Academy of Medical Sciences, Beijing, China) for $16 \mathrm{~h}$ at $4^{\circ} \mathrm{C}$. Bound antibodies were detected using Histofine Simple Stain $\mathrm{PO}^{\circledast}$ Max reagent using diaminobenzidine tetrahydrochloride as the substrate, with sections counterstained with $0.0025 \%$ Mayer's hematoxylin for $2 \mathrm{~min}$ in $37^{\circ} \mathrm{C}$. The immunoreactivity of the lumican protein was scored on the basis of the intensity of the predominant cytoplasmic staining area using the following classification system: 0 , negative; 1 , weakly-positive; 2 , strongly-positive. To examine the associations between lumican expression levels and the clinicopathological features or prognostic factors, the tumors were divided into two groups according to the intensity of staining: Scale 0 , negative group; scales 1 and 2, positive group. All specimens were evaluated by two investigators blinded to the clinical information of the patients.

Statistical analysis. The $\chi^{2}$ test was used to analyze the associations between lumican expression and various prognostic factors. The survival rate was calculated using the Kaplan-Meier method, and the significance of the differences in the survival rate was analyzed by the log-rank test. All statistical analyses were performing using SPSS software version 17.0 (SPSS, Inc., Chicago, IL, USA). $\alpha$ was set at 0.05 , and a two-tailed $\mathrm{P}<0.05$ was considered to indicate a statistically significant difference.

\section{Results}

Expression and location of lumican in human gastric cancer, and adjacent normal gastric tissues. The expression of lumican in the adjacent normal tissues of 55 patient samples was observed to either be negative or weakly-positive, with weakly-positive expression only observed in $10.9 \%(6 / 55)$ of the 55 samples (Fig. 1A). In the present study, lumican expression was localized to the cytoplasm $(58.2 \%, 85 / 146)$ and membrane $(8.2 \%, 12 / 146)$ of the gastric cancer cells (Fig. 1B-D). Of the 146 gastric cancer tissue samples, lumican expression was observed in 66.4\% (97/146), of which $34.9 \%(51 / 146)$ were weakly-positive and $31.5 \%$ (46/146) were strongly-positive. The rate of positive expression in organ metastatic and lymphatic metastatic tissues was $77.8 \%$ (28/36) and 76.5\% (65/85), respectively (Fig. 2).

Expression of lumican and its association with pathological features. According to the WHO 2010 pathological grouping 
Table I. Association between patient characteristics and lumican expression.

Lumican, $\mathrm{n}$

\begin{tabular}{|c|c|c|c|c|c|c|}
\hline \multirow[b]{2}{*}{ Parameter } & \multirow[b]{2}{*}{ All } & & \multirow[b]{2}{*}{$\chi^{2}$ value } & \multirow[b]{2}{*}{ P-value } \\
\hline & & Negative & Weak & Strong & & \\
\hline Age, years & & & & & 4.290 & 0.296 \\
\hline$<40$ & 11 & 7 & 2 & 2 & & \\
\hline $40-60$ & 73 & 23 & 27 & 23 & & \\
\hline$>60$ & 62 & 19 & 22 & 21 & & \\
\hline Sex & & & & & 5.240 & 0.073 \\
\hline Male & 110 & 33 & 37 & 40 & & \\
\hline Female & 36 & 16 & 14 & 6 & & \\
\hline Tumor location & & & & & 6.963 & 0.324 \\
\hline Proximal & 14 & 6 & 3 & 5 & & \\
\hline Mid & 17 & 3 & 10 & 4 & & \\
\hline Distal & 99 & 35 & 34 & 30 & & \\
\hline Diffuse & 16 & 5 & 4 & 7 & & \\
\hline Diameter, $\mathrm{cm}$ & & & & & 7.857 & 0.097 \\
\hline$<5$ & 57 & 16 & 27 & 14 & & \\
\hline $5-10$ & 77 & 29 & 19 & 29 & & \\
\hline$>10$ & 12 & 4 & 5 & 3 & & \\
\hline Organ metastasis & & & & & 7.717 & $0.021^{\mathrm{a}}$ \\
\hline No & 110 & 41 & 41 & 28 & & \\
\hline Yes & 36 & 8 & 10 & 18 & & \\
\hline Depth & & & & & 3.791 & 0.705 \\
\hline Mucosa & 19 & 5 & 10 & 4 & & \\
\hline Submucosa & 28 & 11 & 8 & 9 & & \\
\hline Muscularis & 65 & 21 & 23 & 21 & & \\
\hline Serosa & 34 & 12 & 10 & 12 & & \\
\hline Borrmann type & & & & & 11.290 & 0.186 \\
\hline 0 & 17 & 4 & 8 & 5 & & \\
\hline 1 & 12 & 3 & 8 & 1 & & \\
\hline 2 & 21 & 6 & 7 & 8 & & \\
\hline 3 & 93 & 35 & 26 & 32 & & \\
\hline 4 & 3 & 1 & 2 & 0 & & \\
\hline Lymphatic metastasis & & & & & 13.736 & $0.001^{\mathrm{a}}$ \\
\hline No & 61 & 29 & 22 & 10 & & \\
\hline Yes & 85 & 20 & 29 & 36 & & \\
\hline Histological type & & & & & 7.696 & $0.021^{\mathrm{a}}$ \\
\hline Adenocarcinoma & 102 & 27 & 40 & 35 & & \\
\hline Mucinous/signet-ring cell carcinoma & 44 & 22 & 11 & 11 & & \\
\hline
\end{tabular}

${ }^{\mathrm{a}} \mathrm{P}<0.05$.

standard, gastric cancer was divided into adenocarcinoma (tubular adenocarcinoma and papillary adenocarcinoma), mucinous adenocarcinoma, signet-ring cell carcinoma, mixed carcinoma and others (13). Lumican expression, tissue histology and other clinicopathological parameters were presented in Table I. Tumors were located in proximal (14), middle (17), distal (99), and diffuse (16) areas of stomach. A total of 57 tumors exhibited a diameter $<5 \mathrm{~cm}, 12$ with a diameter $>10 \mathrm{~cm}$, and 99 with a diameter of $5-10 \mathrm{~cm}$. Of these patients, 36 cases exhibited organ metastasis, and 110 did not. A total of 19 tumors had invaded the mucosa, 26 in the submucosa, 65 in the muscularis and 34 in the serosa of the stomach. Borrmann type was categorized into five groups: Borrmann 0, Borrmann I, Borrmann II, Borrmann III and Borrmann IV (14). 17 cases were Borrmann 0, 12 cases were Borrmann I, 21 cases were Borrmann II, 93 cases were 

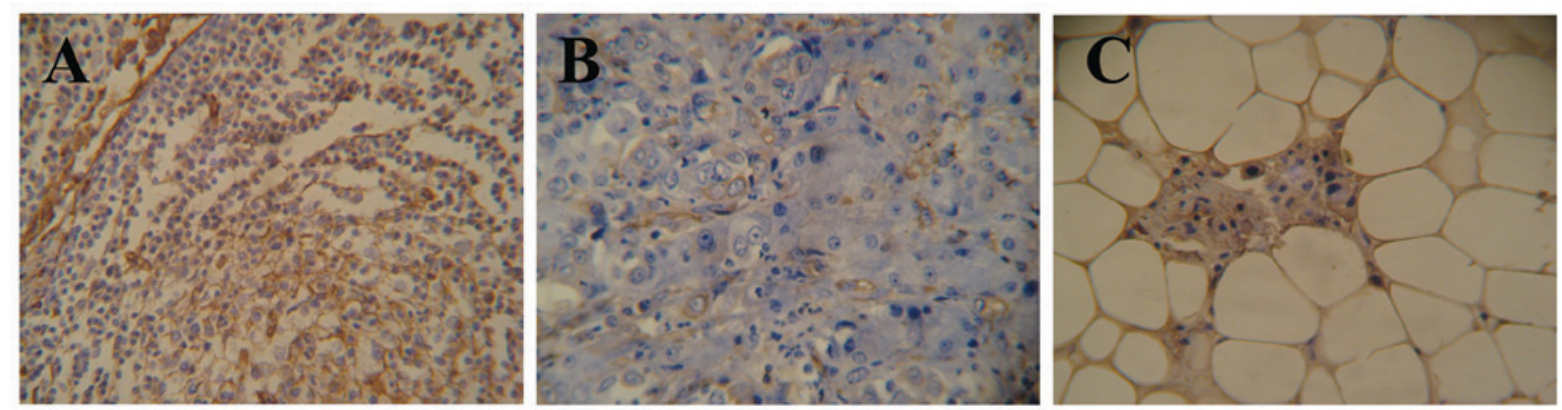

Figure 2. Expression of lumican in gastric cancer metastatic tissues (magnification, $x 400$ ). (A) Expression of lumican in gastric cancer lymphatic metastatic tissue. (B) Expression of lumican in gastric cancer hepatic metastatic tissue. (C) Expression of lumican in gastric cancer greater omentum metastasis.

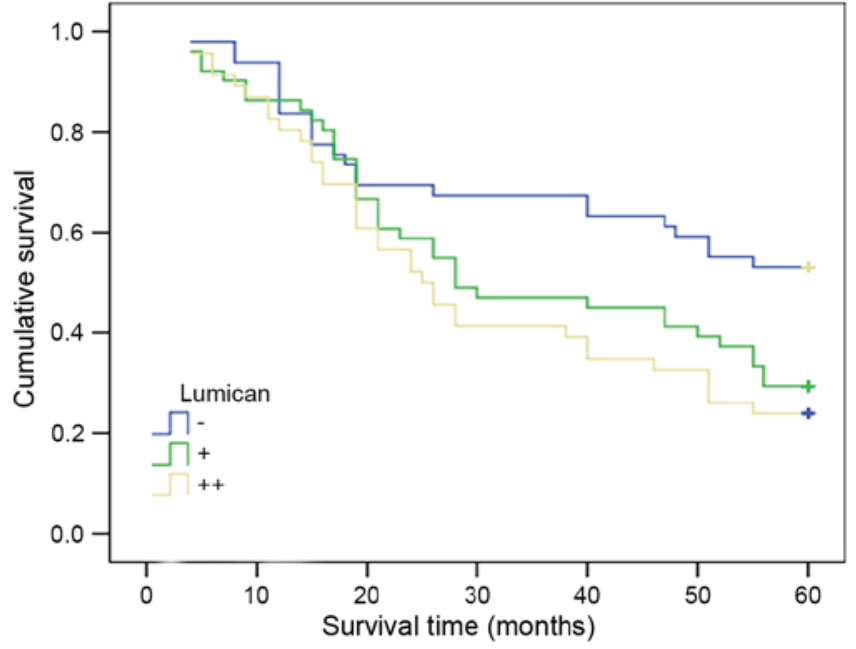

Figure 3. Association between survival rate and lumican expression -, Negative lumican expression; w, weakly-positive lumican expression; + , strongly-positive lumican expression.

Borrmann III, 3 cases were Borrmann IV. A total of 85 cases exhibited lymphatic metastasis, and 61 did not. Pathologically, 102 patients exhibited adenocarcinoma and 44 patients exhibited mucinous carcinoma/signet-ring cell carcinoma. Lumican expression was determined to be significantly associated with organ metastasis, lymphatic metastasis and histological type $(\mathrm{P}<0.05)$, but not with the tumor location, size, invasion depth or the Borrmann type $(\mathrm{P}>0.05)$.

Lumican expression in gastric cancer and its association with long-term survival rate. For the 146 gastric cancer patient samples, in which lumican expression was negative (49 cases), weakly-positive (51 cases) and strongly-positive (46 cases), the median survival time were 46.3, 39.6 and 24.3 months, respectively. Kaplan-Meier survival analysis revealed that the difference was statistically significant amongst the three groups $\left(\chi^{2}=8.492 ; \mathrm{P}=0.014\right.$; Fig. 3 ). There was a negative association between lumican expression and the long-term survival of patients with gastric cancer.

\section{Discussion}

The lumican gene is 338 amino acids long and contains a recognized 18-residue signal peptide of $38 \mathrm{kDa}(15-17)$, which is located at the $12 \mathrm{q} 21.3-\mathrm{q} 22$ area of the 12 th chromosome $(18,19)$. Lumican, as an important member of SLRP, possesses four functional regions: Region I, contains a signal peptide; region II, cysteine-rich; region III, a leucine-rich region that contains 10 leucine-rich repeats; region IV, a cysteine-rich region that combines with an $\mathrm{N}$-terminal cysteine into a disulfide domain (20-23).

Numerous regulatory factors affect the abnormal expression of lumican, with various tumors having differing degrees of lumican expression (24-26). A non-sulfuric or poorly-sulfuric polylactosamine chain has been observed to be attached to lumican in certain pancreatic cancer cell lines (27). Lumican in cancer cells has a polylactosamine chain; these glycosylated lumican proteins promote the proliferation of cancer cells (28). In breast cancer, lumican expression in cancer cells and acrotenic fibroblasts has been observed to be high (29). Lumican expression is closely associated with the degree of tumor cell differentiation, cancer estrogen receptor levels and patient age (30). In the present study, it was observed that, in adjacent normal gastric tissues, the expression of lumican was negative or weakly positive and the majority of positive expression was focal or diffuse, localized in the cytoplasm or at the membrane. In the gastric glands, which are formed primarily of mature cells, the expression of lumican protein was usually negative, and suggesting that the expression of lumican was weak or negative in differentiated non-proliferating cells.

In the 146 gastric cancer samples analyzed in the present study, the majority expressed lumican $(66.4 \%, 97 / 146)$, with that expression concentrated in the cytoplasm or at the membrane. The differential expression of lumican may be associated with damage to normal interstitial tissue and the reconstruction of the tumor stroma in the process of invasion. In colorectal cancer tissues, lumican was diffusely localized in the cytoplasm of the cancer cells and its expression was detected in 99 of the 158 cases (62.7\%) of a previous study (31). During the development of the tumor, lumican promotes the rebuilding of tumor stroma by participating in the biochemical synthesis and degradation of the extracellular matrix (32).

The expression of lumican in patients with organ and lymphatic metastatic tissues was 77.8 (28/36) and $76.5 \%$ $(65 / 85)$, respectively. The expression of lumican in patients without organ metastatic and lymphatic metastatic tissues was $62.7(69 / 110)$ and $52.5 \%(32 / 61)$, respectively. It was observed that the expression of lumican in the patients with 
gastric cancer with organ or lymphatic metastasis were higher compared with those without lymphatic or organ metastasis ( 77.8 vs. $62.7 ; 76.5$ vs. $52.5 \%$ ). These data indicate that lumican expression may be associated with the invasion and metastasis of gastric cancer. As lumican has more non-sulfated or poorly-sulfated polylactosamine side-chains than highly-sulfated keratan sulfate side chains, positive expression in colorectal and pancreatic cancer exhibits more invasive and metastatic characteristics $(33,34)$. Lumican expression was stronger in adenocarcinoma, compared with in mucinous adenocarcinoma or signet-ring cell carcinoma. No incidences of strongly-positive lumican expression were identified in mucinous adenocarcinoma or signet-ring cell carcinoma. Co-adjustment cannot be achieved between lumican and fibroblasts via transforming growth factor- $\beta$ and mothers against decapentaplegic homolog protein signaling, due to a lack of tumor stromal tissues $(35,36)$.

Statistical analysis of patient survival indicated that there is a significant negative association between high lumican expression levels and the long-term survival rate. The stronger the expression of lumican, the poorer the prognosis of the patient. The results of the present study suggested that lumican could be used as a sensitive, independent molecular target to judge the prognosis of patients with gastric cancer, but its expression and regulatory mechanism necessitates further investigation.

In summary, there was a significant association between the expression of lumican and the invasive potential of gastric cancer; thus, lumican could serve as an independent prognostic factor.

\section{Acknowledgements}

The present study was supported by grants from Clinical Research Foundation of Wu Jieping Medical Foundation (grant no. 320.6750.13105) and the Educational Institutions of Heilongjiang Province (grant no. 12541458).

\section{References}

1. Siegel RL, Miller KD and Jemal A: Cancer statistics, 2016. CA Cancer J Clin 66: 7-30, 2016.

2. Chen W, Zheng R, Baade PD, Zhang S, Zeng H, Bray F, Jemal A, Yu XQ and He J: Cancer statistics in China, 2015. CA Cancer J Clin 66: 115-132, 2016.

3. Torre LA, Bray F, Siegel RL, Ferlay J, Lortet-Tieulent J and Jemal A: Global cancer statistics, 2012. CA Cancer J Clin 65: 87-108, 2015.

4. Chen L, Zuo Y, Zhu L, Zhang Y, Li S, Ma F, Han Y, Song H and Xue Y: Peripheral venous blood neutrophil-to-lymphocyte ratio predicts survival in patients with advanced gastric cancer treated with neoadjuvant chemotherapy. Onco Targets Ther 10: 2569-2580, 2017.

5. Chen S and Birk DE: The regulatory roles of small leucine-rich proteoglycans in extracellular assembly. FEBS J 280: 2120-2137, 2013.

6. Moreth K, Iozzo RV and Schaefer L: Small leucine-rich proteoglycans orchestrate receptor crosstalk during inflammation. Cel Cycle 11: 2084-2091, 2012.

7. Baghy K, Dezso K, László V, Fullár A, Péterfia B, Paku S, Nagy P, Schaff Z, Iozzo RV and Kovalszky I: Ablation of the decorin gene enhances experimental hepatic fibrosis and impairs hepatic healing in mice. Lab Invest 91: 439-451, 2011.

8. Schaefer L and Iozzo RV: Small leucine-rich proteoglycans, at the crossroad of cancer growth and inflammation. Curr Opin Genet Dev 22: 56-57, 2012.
9. de Wit M, Carvalho B, Delis-van Diemen PM, van Alphen C, Beliën JAM, Meijer GA and Fijneman RJA: Lumican and versican protein expression are associated with colorectal adenoma-to-carcinoma progression. PLoS One 12: e0174768, 2017.

10. Kalamajski S and Oldberg A: The role of small leucine-rich proteoglycans in collagen fibrillogenesis. Matrix Biol 29: 248-p253, 2010.

11. Nikitovic D, Papoutsidakis A, Karamanos NK and Tzanakakis GN: Lumican affects tumor cell functions, tumor-ECM interactions, angiogenesis and inflammatory response. Matrix Biol 35: 206-214, 2014.

12. Appunni S, Anand V, Khandelwal M, Seth A, Mathur S and Sharma A: Altered expression of small leucine-rich proteoglycans (Decorin, Biglycan and Lumican): Plausible diagnostic marker in urothelial carcinoma of bladder. Tumour Biol 39: 1010428317699112, 2017.

13. Xiao LL and Xiao XY: Histological and molecular classification of gastric cancer and personalized therapy. WCJD 23: 4141-4149, 2015.

14. Liu JW, Liu HL and Zhang T: Research progress of molecular type of gastric cancer. Chin J Clin 8: 4444-4448, 2014.

15. Guggenheim JA, Zayats T, Hammond C and Young TL: Lumican and muscarinic acetylcholine receptor 1 gene polymorphisms associated with high myopia. Eye (Lond) 24: 1411-1412, 2010.

16. Matsuda Y, Yamamoto T, Kudo M, Kawahara K, Kawamoto M, Nakajima Y, Koizumi K, Nakazawa N, Ishiwata T and Naito Z: Expression and roles of lumican in lung adenocarcinoma and squamous cell carcinoma. Int J Oncol 33: 1177-1185, 2008.

17. Hayashi Y, Call MK, Chikama T, Liu H, Carlson EC, Sun Y, Pearlman E, Funderburgh JL, Babcock G, Liu CY, et al: Lumican is required for neutrophil extravasation following corneal injury and wound healing. J Cell Sci 123: 2987-2995, 2010.

18. Kalamajski S and Oldberg A: Homologous sequence in lumican and fibromodulin leucine-rich repeat 5-7 competes for collagen binding. J Biol Chem 284: 534-539, 2009.

19. Nikitovic D, Katonis P, Tsatsakis A, Karamanos NK and Tzanakakis GN: Lumican, a small leucine-rich proteoglycan. IUBMB Life 60: 818-823, 2008.

20. Seomun Y and Joo CK: Lumican induces human corneal epithelial cell migration and integrin expression via ERK 1/2 signaling. Biochem Biophys Res Commun 372: 221-225, 2008.

21. Nikitovic D, Berdiaki A, Zafiropoulos A, Katonis P, Tsatsakis A, Karamanos NK and Tzanakakis GN: Lumican expression is positively correlated with the differentiation and negatively with the growth of human osteosarcoma cells. FEBS J 275: 350-361, 2008.

22. Chakravarti S, Stallings RL, SundarRaj N, Cornuet PK and Hassell JR: Primary structure of human Lumican (keratan sulfate proteoglycan) and localization of the gene (LUM) to chromosome 12q21.3-q22. Genomics 27: 481-488, 1995.

23. Kafienah W, Cheung FL, Sims T, Martin I, Miot S, Von Ruhland C, Roughley PJ and Hollander AP: Lumican inhibits collagen deposition in tissue engineered cartilage. Matrix Biol 27: 526-534, 2008.

24. Sharma B, Ramus MD, Kirkwood CT, Sperry EE, Chu PH, Kao WW and Albig AR: lumican exhibits anti-angiogenic activity in a context specific manner. Cancer Microenviron 6: 263-271, 2013.

25. Kashyap MK, Marimuthu A, Peri S, Kumar GS, Jacob HK, Prasad TS, Mahmood R, Kumar KV, Kumar MV, Meltzer SJ, et al: Overexpression of periostin and lumican in esophageal squamous cell carcinoma. Cancers 2: 133-142, 2010.

26. Colak D, Chishti MA, Al-Bakheet AB, Al-Qahtani A, Shoukri MM, Goyns MH, Ozand PT, Quackenbush J, Park BH and Kaya N: Integrative and comparative genomics analysis of early hepatocellular carcinoma differentiated from liver regeneration in young and old. Mol Cancer 9: 146, 2010.

27. Li X, Truty MA, Kang Y, Chopin-Laly X, Zhang R, Roife D, Chatterjee D, Lin E, Thomas RM, Wang H, et al: Extracellular lumican inhibits pancreatic cancer cell growth and is associated with prolonged survival after surgery. Clin Cancer Res 20: 6529-6540, 2014

28. Li X, Roife D, Kang Y, Dai B, Pratt M and Fleming JB: Extracellular lumican augments cytotoxicity of chemotherapy in pancreatic ductal adenocarcinoma cells via autophagy inhibition. Oncogene 35: 4881-4890, 2016.

29. Eshchenko TY, Rykova VI, Chernakov AE, Sidorov SV and Grigorieva EV: Expression of different proteoglycans in human breast tumors. Biochemistry (Moscow) 72: 1016-1020, 2007. 
30. Kang Y, Roife D, Lee Y, Lv H, Suzuki R, Ling J, Rios Perez MV, Li X, Dai B, Pratt M, et al: Transforming Growth Factor- $\beta$ limits secretion of lumican by activated stellate cells within primary pancreatic adenocarcinoma tumors. Clin Cancer Res 22: 4934-4946, 2016.

31. Seya T, Tanaka N, Shinji S, Yokoi K, Koizumi M, Teranishi N, Yamashita K, Tajiri T, Ishiwata T and Naito Z: Lumican expression in advanced colorectal cancer with nodal metastasis correlates with poor prognosis. Oncol Rep 16: 1225-1230, 2006.

32. Radwanska A, Litwin M, Nowak D, Baczynska D, Wegrowski Y, Maquart FX and Malicka-Blaszkiewicz M: Overexpression of lumican affects the migration of human colon cancer cells through up-regulation of gelsolin and filamentous actin reorganization. Exp Cell Res 318: 2312-2323, 2012.

33. Yamamoto T, Matsuda $Y$, Kawahara $K$, Ishiwata $T$ and Naito $Z$ : Secreted $70 \mathrm{kDa}$ lumican stimulates growth and inhibits invasion of human pancreatic cancer. Cancer Lett 320: 31-39, 2012.
34. de Wit M, BeltEJ, Delis-van Diemen PM, Carvalho B, Coupé VM, Stockmann HB, Bril H, Beliën JA, Fijneman RJ and Meijer GA: Lumican and versican are associated with good outcome in stage II and III colon cancer. Ann Surg Oncol 20 (Suppl 3): S348-S359, 2013.

35. Nikitovic D, Chalkiadaki G, Berdiaki A, Aggelidakis J, Katonis P, Karamanos NK and Tzanakakis GN: Lumican regulates osteosarcoma cell adhesion by modulating TGF $\beta 2$ activity. Int J Biochem Cell Biol 43: 928-935, 2011.

36. Naito Z: Role of the small leucine-rich proteoglycan (SLRP) family in pathological lesions and cancer cell growth. J Nippon Med Sch 72: 137-145, 2005. 